\title{
SISTEM PENYEWAAN RENTAL MOBIL DAN PENGOLAHAN DATA PADA JENNETE RENT CAR
}

\author{
Ari Kurniaedi ${ }^{1}$, Laksana Priyo Abadi $^{2}$, Adhityo Kuncoro ${ }^{3}$ \\ Program Studi Informatika, Fakultas Teknik dan Ilmu Komputer, Universitas Indraprasta PGRI \\ Jalan Raya Tengah No 80, Kelurahan Gedong, Pasar Rebo, Jakarta Timur \\ ari.kurnia.edi666@gmail.com ${ }^{1}$, laksanarioabadi@gmail.com ${ }^{2}$, adhityokuncoro@yahoo.com ${ }^{3}$.
}

\begin{abstract}
Abstrak
Permasalahan dari sistem penyewaan rental mobil di Jennete Rent Car yaitu lambatnya pencarian pendataan ketersediaan mobil, data mobil, data peminjam, serta proses laporan penyewaan mobil yang diakibatkan karena sistem yang diterapkan masih bersifat manual dan belum terkomputerisasi. Dari persoalan tersebut, penulis tertarik untuk mengembangkan sistem penyewaan rental mobil di Jennete Rent Car yang ada saat ini sehingga dapat mengatasi kekurangan yang ada. Seiring dengan semakin canggihnya teknologi yang berkembang, komputer telah mendorong terjadinya perubahan ilmu, baik dalam kajian ataupun implementasi dilapangan. Peran teknologi komputer sangat diperlukan oleh berbagai perusahaan. Mengingat kebutuhan akan peningkatan efisiensi dan efektifitas dari setiap kegiatan dalam instansi tidak dapat diukur dan dilakukan secara cepat dan akurat tanpa adanya dukungan teknologi tersebut. Akurasi data, kecepatan waktu dan relevansi menjadi penentu kualitas informasi yang dihasilkan. Dengan menggunakan metode pengembangan sistem yaitu Waterfall dalam penelitian ini adalah dengan tahapan-tahapan seperti rekayasa sistem, analisis, desain, coding, testing, dan maintenance. Hasil dari penelitian ini adalah menciptakan aplikasi untuk penyewaan mobil efektif dan efisien.
\end{abstract}

Kata Kunci: Sistem, Penyewaan, Mobil

\begin{abstract}
The problem of car rental system in Jennete Rent Car is slow searching of car availability, car data, borrower data, as well as car rental report process due to the applied system is still manual and has not been computerized. From the issue, the authors are interested to develop a car rental system in the existing Jennete Rent Car that can overcome the shortage. As the technology grows, the computer encourages the changing of knowledge, whether in the study or implementation of field. The role of computer technology is indispensable by various companies. Given the need for increased efficiency and effectiveness of each activity in the institution cannot be measured and done quickly and accurately without the support of such technology. Data accuracy, time speed and relevance become the quality determinant of the generated information. By using the system development method that is Waterfall in the research is with stages such as system engineering, analysis, design, coding, testing, and maintenance. The result of this research is creating an application for effective and efficient car rental.
\end{abstract}

Keywords: System, Rentalcar, Car.

\section{PENDAHULUAN}

Sejalan dengan teknologi komputer hampir setiap sektor, instansi atau perusahaan banyak menggunakan komputer dalam kegiatannya. Demikian juga dengan proses penyewaan kendaraan mobil, dimana perangkat komputer sangat dibutuhkan, guna memudahkan membuat laporan atau dokumen serta arsip dan data operasional lainnya yang sangat berguna untuk membantu para pekerja sehari-harinya. Karena rental kendaraan mobil pada saat sekarang ini sama pentingnya dengan teknologi komputer hampir disetiap sektor, instansi atau perusahaan maupun pribadi banyak memerlukan alat transportasi kendaraan mobil guna memerlukan usahanya. (Sutabri, 2012) Sistem adalah sekelompok komponen dan elemen yang digabungkan menjadi satu untuk mencapai tujuan tertentu. (Subekti, 2014) Penyewaan adalah suatu kegiatan dalam diantara dua belah pihak antara diri nya dengan pihak lainnya dalam proses peminjaman atau penyewaan suatu barang dalam waktu yang 
sudah disepakati diantara kedua belah pihak dan dengan pembayaran yang telah disepakati pula oleh kedua belah pihak. Sejalan dengan teknologi komputer hampir setiap sektor, instansi, atau perusahaan banyak menggunakan dalam kegiatannya. Demikian juga dengan proses pennyewaan mobil di Jennete Rent Car, dimana perangkat komputer sangat dibutuhkan guna memudahkan membuat laporan dokumen setiap arsip dan data operasional lainnya yang sangat berguna untuk membantu kerja karyawan setiap harinya. Dengan adanya sistem penyewaan mobil yang telah terkomputerisasi banyak sekali keuntungan yang diperoleh oleh pihak Jennete Rent Car seperti informasi yang tersedia dapat diketahui dengan cepat dan tidak akan terjadi penyewaan mobil pada merk atau tipe dan nomor polisi yang sama oleh pelanggan lain dan juga dapat mengetahui dengan cepat apakah mobil yang disewa tersebut sudah dikembalikan atau belum serta waktu yang diperlukan lebih efesien serta memudahkan pihak Jennete Rent Car dalam mencatat pelaporan setiap bulannya.

\section{PENELITIAN YANG RELEVAN}

Dalam penelitian yang berjudul Analisis Penerapan Good Governance dalam proses pengadaan barang dan jasa provinsi kepulauan Riau tahun anggaran 2013 (Studi pada unit layanan pengadaan) dengan peneliti yang bernama Tasori memiliki hasil penelitian untuk mengetahui bagaimana proses pelaksanaan pengadaan barang dan jasa pada Pemerintah Provinsi Kepulauan Riau di tahun anggaran 2013 terutama pada proses pemilihan penyedia barang dan jasa yang menjadi kewenangan Tim Pokja ULP dan kendala-kendala apa saja yang penulis temukan dalam pelaksanaanya. Dan ada penelitian kedua yang berjudul Rancang Bangun sistem Informasi Survei Alumni Berbasis Web Pada Program Studi Diploma III Manajemen Informatika Unsyiah dengan peneliti yang bernama Melia Rosa memiliki hasil penelitian terhadap Rancang Bangun Sistem Informasi Survei Alumni Berbasis Web Pada Program Studi Diploma III Manajemen Informatika Unsyiah, tujuannya untuk mempermudah dalam pendataan serta penyimpanan data-data Unsyiah.

\section{METODE PENELITIAN}

Metodologi pengembangan sistem yang digunakan Waterfall (Jogiyanto, 2010), dengan tahapan seperti gambar sebagai berikut:

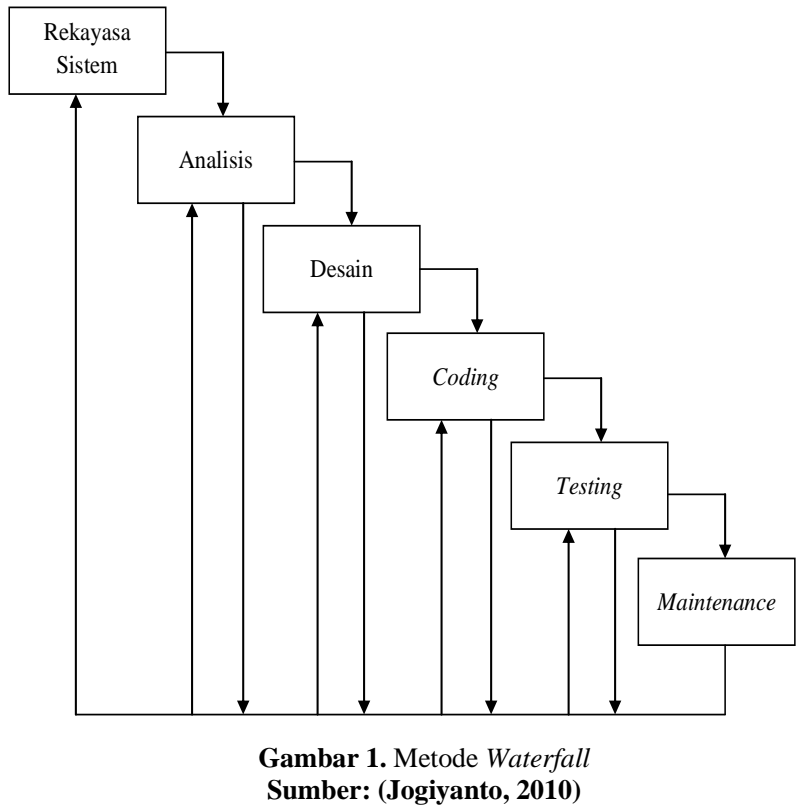

Berikut ini adalah penjelasan dari tahapan-tahapan yang terdapat dalam metode Waterfall: 
1. Rekayasa Sistem, merupakan tahap awal dari pembangunan perangkat lunak, yaitu menetapkan segala hal yang diperlukan dalam pelaksanaan pembangunan perangkat lunak dan menentukan apakah sistem benar-benar dibutuhkan.

2. Analisis, merupakan tahap dimana rekayasa perangkat lunak menganalisa hal-hal yang diperlukan dalam pembuatan suatu aplikasi yang akan dibuat.

3. Desain, merupakan tahap penterjemahan dari keperluan data-data yang telah dianalisa kedalam bentuk yang mudah dimengerti oleh pemakai.

4. Coding, adalah tahap penterjemahan data pemecah masalah yang telah dirancang kedalam bahasa pemograman komputer yang telah ditentukan.

5. Testing, merupakan tahap pengujian terhadap perangkat lunak yang telah selesai dibuat untuk menemukan kesalahan-kesalahan atau kekurangan yang terdapat di dalam sistem. Pada pengujian ini peneliti menggunakan pengujian black box. Pengujian black box berusaha menemukan kesalahan dalam kategori:

a. Fungsi-fungsi yang tidak benar atau hilang.

b. Kesalahan interface, kesalahan dalam tampilan layar.

c. Kesalahan pada struktur data atau akses database.

d. Kesalahan performansi, kesalahan inisialisasi dan tujuan akhir.

6. Maintenance, yaitu tahap akhir dimana perangkat lunak yang sudah selesai dan mengalami perubahan atau penambahan sesuai dengan permintaan. Bagian ini merupakan bagian terujung dari siklus pengembangan sistem laporan data administrasi. Pada tahapan ini dilakukan kegiatan corrective maintenance, yaitu mengkoreksi kesalahan pada perangkat lunak yang baru diketahui pada saat perangkat lunak dipergunakan. Dengan adanya corrective maintenance terhadap sistem laporan data penyewaan, maka kesalahan-kesalahan yang terdapat pada sistem penyewaan ini dapat diperbaiki.

\section{HASIL DAN PEMBAHASAN}

Pada sistem informasi penyewaan mobil di Jennete Rent Car ini ternyata mempunyai beberapa kelemahan karena sistem yang digunakan belum sepenuhnya terkomputerisasi.

1. Sistem yang diterapkan atau yang sedang berjalan mengenai penyewaan mobil maupun data pelanggan masih menggunakan sistem manual. Jika dilihat dari segi fungsi penyewan mobil, supaya mudah mendapatkan informasi mengenai perkembangan dari produktivitas perusahaan, maka sebaiknya digunakan sistem informasi secara komputerisasi.

2. Pengolahan data dengan menggunakan sistem manual ini dapat menyebabkan terjadinya kekurangan dan kesalahan dalam pengolahan data, sehingga terjadi kesulitan dalam memperbaiki atau memodifikasi data tersebut, juga akan memakan waktu yang lama untuk melakukan proses data.

3. Dengan menggunakan sistem tersebut diatas, maka perusahaan sering mengalami masalah dalam pembuatan laporan yang khususnya bagian penyewaan. Sebab dengan sistem tersebut data yang diperoleh tidak efisien, karena sistem yang sedang berjalan masih secara manual.

\section{Alternatif Penyelesaian Masalah}

Untuk mencari solusi dalam permasalahan yang ada maka penulis membuat suatu sitem yang akan membantu dalam menyelesaikan masalah tersebut. Berdasarkan analisa sistem yang sedang berjalan saat ini penulis melihat beberapa kelemahan dan pokok permasalahan yang terdapat pada sistem penyewaan rental mobil di atas, maka penulis memberikan saran beberapa alternatif penyelesaian masalah diantaranya:

1. Adanya media penyimpanan dalam bentuk database sehingga untuk proses pembuatan laporan penyewaan dapat menghasilkan informasi yang cepat, akurat dan relevan. 
2. Sistem baru ini tampilannya mudah untuk di operasikan karena masing-masing dari file sudah dikelompokan berdasarkan bagian-bagiannya.

3. Mempermudah dalam memberikan laporan penyewaan rental mobil yang lebih akurat di Jennete Rent Car.

\section{Diagram Konteks}

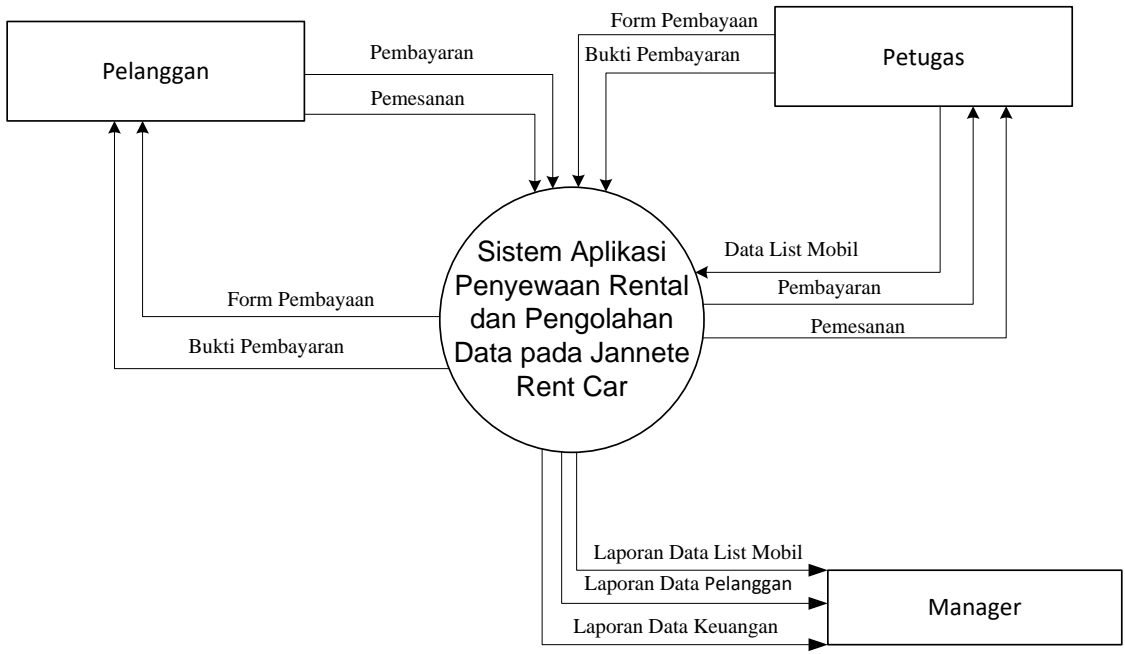

Gambar 2. Diagram Konteks

\section{Normalisasi}

(Pahlevi, 2013) Normalisasi adalah suatu teknik untuk merancang suatu tabel basis data agar suatu susunan tabel tersebut baik agar tidak terjadi nya redudansi data. Berikut bentuk normalisasi dari sistem informasi penyewaan rental mobil di Jennete Rent Car:
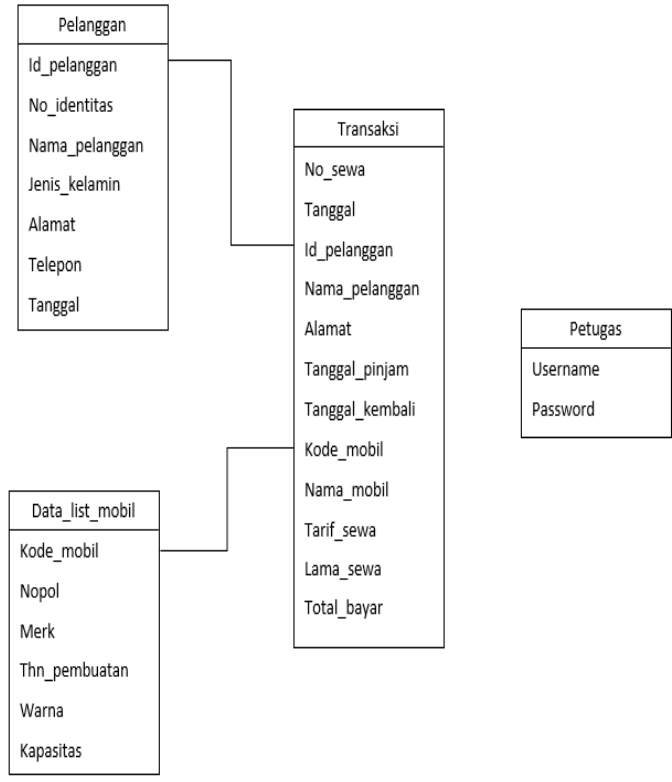

Gambar 3. Normalisasi 


\section{Entity Relationship Diagram (ERD)}

(Shalahudin, 2015) Entity Relationship Diagram adalah Suatu diagram yang menghubungkan satu entitas dengan entitas lain nya, yang dimana setiap entitas tersebut memiliki atribut masing-masing. Didalam diagram itu terdapat cardinality ratio nya dalam menentukan banyaknya korelasi disetiap entitas.

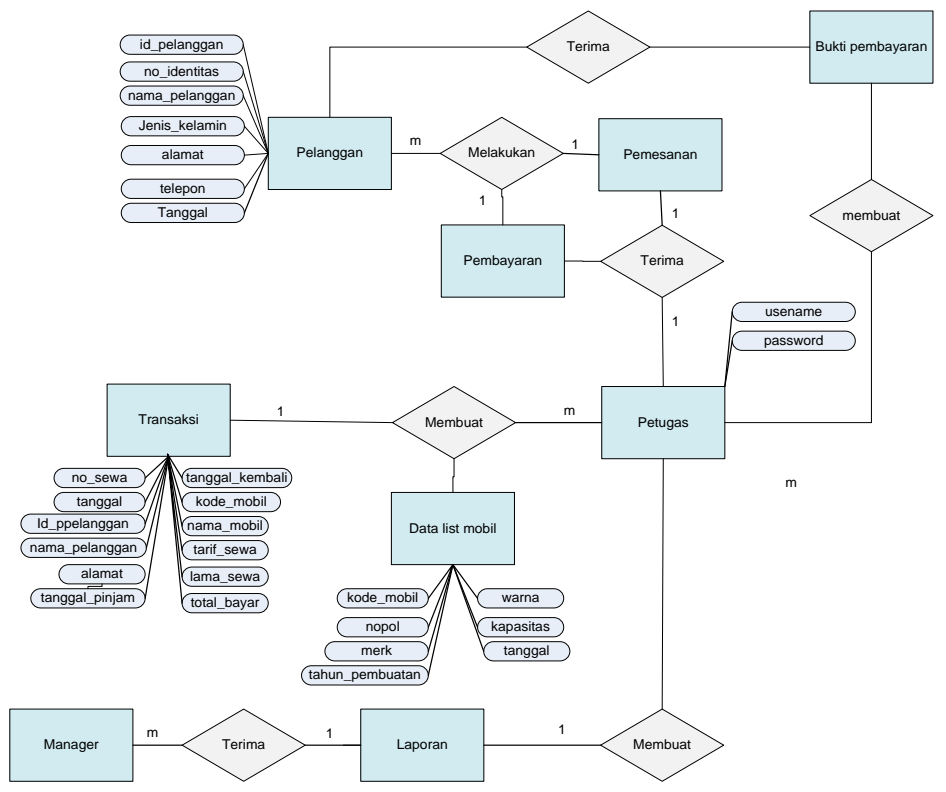

Gambar 4. Entity Relationship Diagram

\section{Tampilan Layar Log In}

\section{LOGIN}

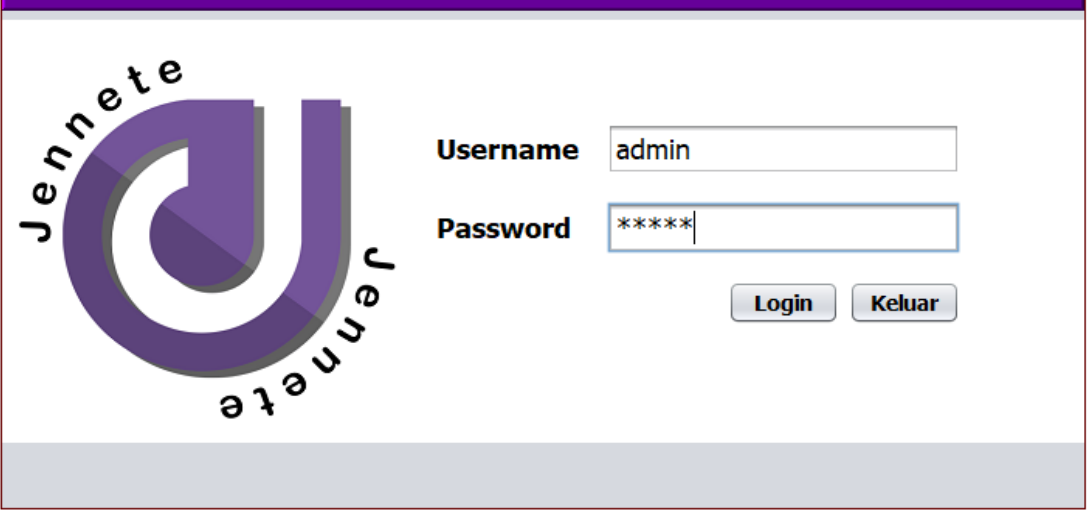

Gambar 5. Tampilan Layar Log In

Tampilan ini terdapat pada awal program. Menu login digunakan sebagai kata kunci sebelum kita memasuki program utama. Agar tidak sembarang orang dapat mengakses program ini. Sehingga dalam Form menu kerahasiaannya tetap terjaga dengan baik. Apabila pengguna dapat memasukkan nama pengguna dan kata kunci dengan tepat, maka menu utama akan tampil dan program siap untuk dijalankan. 


\section{Tampilan Layar Data Peminjam Mobil}

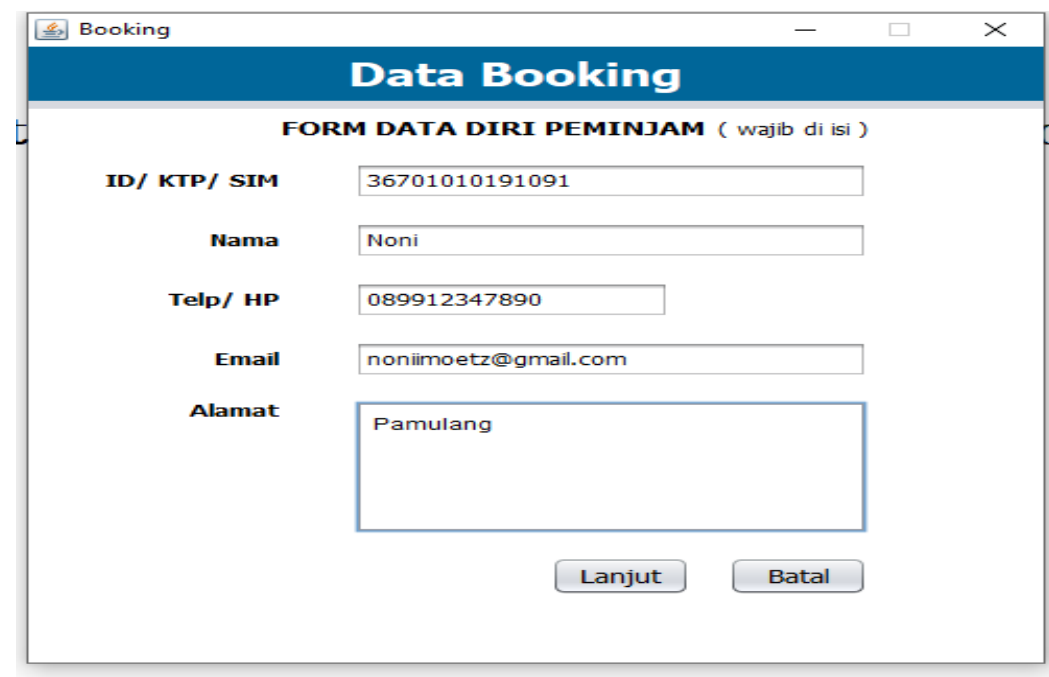

Gambar 6. Tampilan Layar Data Peminjam Mobil

Layar di atas menampilkan tampilan form data Peminjam. Pada layar form data peminjam untuk menginput data peminjam yang terdiri dari ID/KTP/SIM, Nama, No Telp, Email, Alamat

\section{Tampilan Layar Data Pemesanan Mobil}

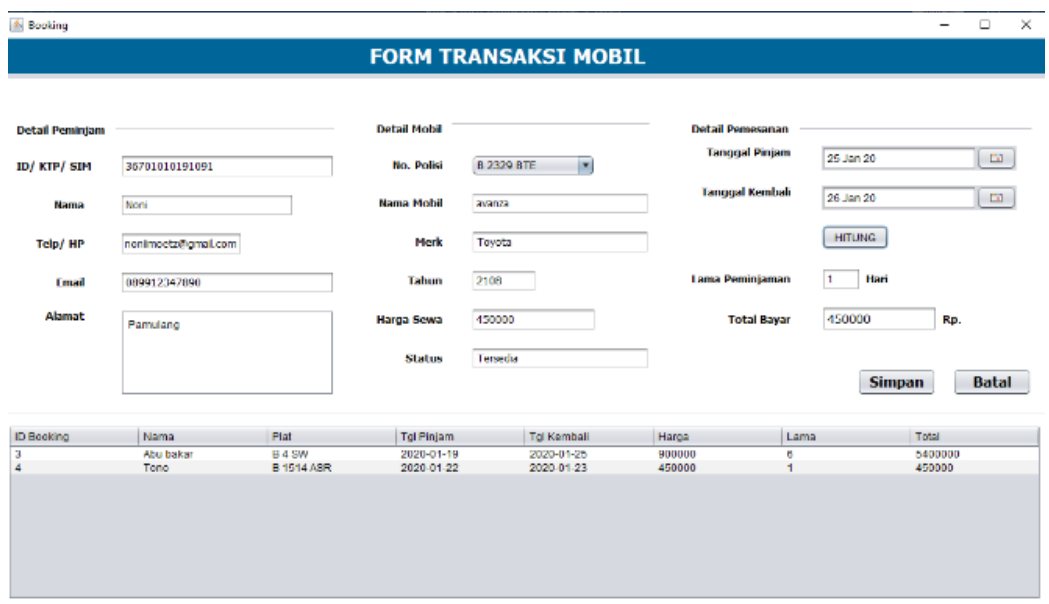

Gambar 7. Tampilan Layar Data Pemesanan Mobil

Layar di atas menampilkan tampilan form data pemesanan mobil. Pada layar form data pemesanan mobil untuk menginput data pemesanan mobil yang terdiri dari ID Booking, Nama, Plat, Tgl Pinjam, Tgl Kembali, Harga, Lama, dan Total Harga. 


\section{Tampilan Laporan Data Penyewaan Mobil}

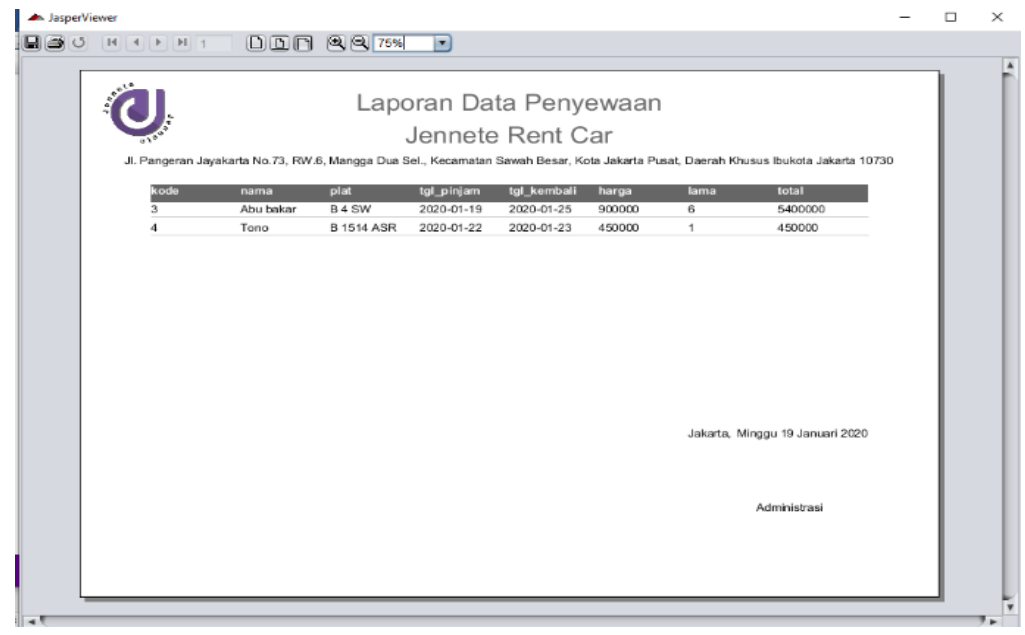

Gambar 8. Tampilan Laporan Data Penyewaan Mobil

Layar di atas menampilkan tampilan form laporan data penyewaan mobil. Pada layar form laporan data penyewaan mobil terdapat informasi data penjualan yang terdiri dari ID Booking, Nama, Plat, Tgl Pinjam, Tgl Kembali, Harga, Lama dann Total.

\section{SIMPULAN}

Sistem informasi penyewaan mobil dapat mempermudah dalam memberikan informasi kepada penyewa. Dan sistem informasi penyewaan mobil diharapkan dapat mempermudah dalam pencarian data mobil dan juga dalam menyajikan informasi yang dihasilkan lebih akurat dan tepat waktu. Sehingga Sistem ini dapat mempermudah dalam proses pengolahan data transaksi, peminjaman, pengembalian dan pembuatan laporan.

\section{DAFTAR PUSTAKA}

Jogiyanto. (2010). Analisis \& Desain Sistem. Yogyakarta: Andi Offset.

Pahlevi, D. S. M. (2013). Tujuh Langkah Praktis Pembangunan Basis Data. Jakarta: Elex Media Komputindo.

Shalahudin, A. . R. dan. (2015). Rekayasa Perangkat Lunak Terstruktur dan Berorientasi Objek. Bandung: Informatika Bandung.

Subekti. (2014). Aneka Perjanjian. Bandung: Citra aditya Bakti.

Sutabri, Tata. (2012). Analisis Sistem Informasi. Yogyakarta: Andi Offset. 